\title{
Polifenoller, Mikrobiyota ve Diyabet
}

\author{
Polyphenols, Microbiota and Diabetes
}

\section{Serpil Özsoy ${ }^{1}$}

Geliş tarihi/Received: 18.09.2019 • Kabul tarihi/Accepted: 14.12.2019

\section{ÖZET}

Mikrobiyota; konak üzerinde/içinde yaşayan mikroorganizma topluluğu olarak tanımlanmaktadır. Son yıllarda bağırsak mikrobiyotasının fizyolojik etkileri en çeşitli ve fazla bakteri kolonizasyonuna sahip bölge olması nedeni ile oldukça ilgi görmektedir. Bağırsak mikrobiyotasındaki çeşitlilik ve denge; diyabet ve obezite gibi tüm dünyada epidemi boyutuna ulaşmış hastalıkların patogenizinde yer almaktadır. Doğum şekli, antibiyotik kullanımı, yaşam tarzı ve beslenme alışkanlıkları; mikrobiyota kompozisyonunu etkileyen faktörler arasındadır. Beslenme alışkanlıkları mikrobiyota kompozisyonunu etkileyen en önemli değiştirilebilir risk faktörü beslenme alışkanlıklarıdır. Yüksek posalı, düşük yağlı, Akdeniz tarzı beslenme ve pre- veprobiyotiklerin kullanımı intestinal mikrobiyota sağlığı, çeşitliliği ve dengesi üzerinde olumlu etkiye sahiptir. Kronik hastalıkların prevalansı ve disbiyoz gelişimi ile ters ilişki gösteren Akdeniz diyeti, DASH (Dietary Approaches to Stop Hypertension) diyeti gibi sağlıklı beslenme modelleri; polifenol içeriği yüksek sebze ve meyve tüketiminin fazla olduğu beslenme modelleridir. Polifenoller vücutta birçok biyolojik faaliyette rol alan biyoaktif besin bileşenleri olarak tanımlanmaktadır. Fenolik yapıdaki bu bileşiklerin \%90-95'i kolonik mikrobiyota tarafından metabolize edilerek biyolojik aktif metabolitleri üretilir. Bu metabolitlerin kolonositler ve patojen bakteriler üzerine olan etkileri nedeni ile bağırsak mikrobiyotası ve polifenoller arasında çift yönlü bir ilişki vardır. Ayrıca polifenoller karbonhidratların metabolizması ve insülin sinyalizasyon yolaklarının regülasyonunun sağlanmasında ve antioksidan özellikleriyle $\beta$-hücre fonksiyonunun korunmasında etkin rol oynamaktadır. Polifenoller hem mikrobiyota kompozisyonu hem de diyabet patogenezindeki olumlu potansiyel etkileri nedeni ile hastalığın tedavisi ve önlenmesinde birincil, ikincil ve üçüncül koruma düzeyinde tıbbi beslenme tedavisinin önemli bir bileşenidir.

Anahtar kelimeler: Polifenoller, mikrobiyota, diyabet, disbiyoz, diyet bileşenleri

\section{ABSTRACT}

Microbiota is defined as a community of microorganisms living on/within the host. In recent years, the physiological effects of intestinal microbiota are interesting research topic because of its microbial diversity. The microbial diversity and balance are closely associated with development of diabetes and obesity. The intestinal microbiota composition is effected by several factors such as delivery method, antibiotic use, lifestyle and eating habits. Eating habit is the most important replaceable risk factor for microbial diversity. High fibre, low fat diets, Mediterranean diet style, use of pre/probiotics have positive effect on intestinal microbiota health, diversity and balance. Healthy diet models such as Mediterranean diet and DASH (Dietary Approaches to Stop Hypertension) diet have inverse relationship with chronic diseases prevalence and development of dysbiosis. These healthy diet models have high polyphenol content from fruits and vegetables. Almost 90-95\% of dietary

1. İletişim/Correspondence: Yakın Doğu Üniversitesi, Sağllk Bilimleri Fakültesi, Beslenme ve Diyetetik Bölümü, Lefkoşa, KKTC

E-posta: serpil_ozsoy@hotmail.com • $\odot$ https://orcid.org/0000-0001-9518-5172 
polyphenols are metabolized by colonic microbiota to their biologically active metabolites. These metabolites have effect on colonocytes and pathogen microorganisms, because of these effects and their metabolism there is a bidirectional interaction between polyphenols and microbiota. In addition, polyphenols play an active role in the regulation of carbohydrate metabolism, regulation of insulin signaling pathways and in the maintenance of $\beta$ - cell function with their antioxidants properties. Polyphenols are an important component of medical nutrition therapy at the level of primary, secondary and tertiary protection in the treatment and prevention of the disease because of the potential positive effects both on microbiota composition and pathogenesis of diabetes.

Keywords: Polyphenols, microbiota, diabetes, dysbiosis, dietary components

\section{GíRiş}

İnsan barsağında $10^{14}$ bakteri hücresi bulunmaktadır ve bu çeşitlimikrobiyomdan türetilen toplam gen sayısı tüm insan genomununkini en az 100 kat aşmaktadır (1). Mikrobiyota; insan vücudunda yaşayan kolektif mikrobiyal topluluk olarak tanımlanmaktadır (2). Yapılan analizler sonucunda vücudun farklı bölgelerindeki bakteri kolonizasyonunun farklı olduğu ve kolonik mikrobiyotanın en yoğun ve çeşitli kısım olduğu ortaya konmuştur (3). Mikrobiyal kolonizasyon vücudun farklı anatomik bölgelerine göre farklılık göstermektedir. İnsan vücudunda yedi baskın türün bulunduğu analiz edilmiştir; Actinobacteria, Firmicutes, Proteobacteria, Bacteroidetes, Fusobacteria, Verrucomicrobia, Archaea (4). Araştırmacılar, son yıllarda bağırsak mikrobiyotasının obezite, diyabet, kardiyovasküler hastalık (KVH), hipertansiyon, inflamatuvar bağırsak hastalıkları, alerji ve astım gibi birçok hastalıkla olan ilişkisini, immün sistem ve insan sağlığı üzerinde önemli düzenleyici rolünü vurgulamaktadır (5).

Diyabet,dünyaçapındaprevalansıartanönemlibirhalk sağlığı sorunudur. Uluslararası Diyabet Federasyonu (International Diabetes Foundation [IDF]) tarafindan 2017 yılında yayınlanan 'Diyabet Atlası'nda dünyada 425 milyon diyabetli olduğu belirtilmiş ve bu rakamın 2045 yllında 629 milyona yükseleceği öngörülmüştür (6). Tüm diyabet vakalarının \%90'ını tip 2 diyabetikler oluşturmaktadır. Sedanter yaşam tarzı, yüksek yağ ve düşük posa içeren beslenme alışkanlıkları, obezite ve tip 2 diyabet gelişimine katkıda bulunan başlıca değiştirilebilir risk faktörlerindendir (7). Son yıllarda yapılan çalışmalarda bağırsak mikrobiyotasının diyabet gelişiminde önemli bir rolünün olduğu vurgulamaktadir (8).

Genetik faktörler, cinsiyet, etnik köken, yaş, antibiyotik kullanımı, genel sağllk durumu ve beslenme alışkanlıkları bağırsak mikrobiyotasının dengesini etkileyen en önemli faktörlerdir (9). Yeterli posa alımı ile birlikte polifenol alımının yüksek olmasının bağırsak mikrobiyotası üzerinde olumlu etkileri olduğunu gösteren çalışmalar mevcuttur. Yeterli ve dengeli beslenme alışkanlıklarıyla yüksek posa ve polifenol alımının bağırsak mikrobiyotasını olumlu yönde etkileyerek, diyabet ve diğer bulaşıcı olmayan kronik hastalıkların prevalansının azalmasında önemli rol oynadığı ileri sürülmektedir (10). Bu derleme yazıda diyabette mikrobiyota ve polifenollerin etkisi irdelenecektir.

\section{Bağırsak Mikrobiyotası ve Sağlık Üzerine Etkileri}

Mikrobiyota kavramı ile ilgili olarak kommensal, simbiyotik ve patojenik mikroorganizmaların vücudumuzu bizimle paylaştığı ancak hastalık ve sağlık durumlarında belirleyici faktör olarak göz ardı edildikleri ifade edilmektedir. Vücudumuzda $\% 10$ insan hücresi, \%90 bakteri hücresi bulunmaktadır. İnsan ve bakteri hücrelerinin ayrı ayrı fonksiyonları düşünüldüğünde bir araya geldikleri zaman oluşturdukları yapı 'Süper Organizma' olarak adlandırılmaktadır (11). Mikrobiyal kompozisyon yaşamboyunca çevreselveçevreselolmayanfaktörlere yanıt olarak değişkenlik gösterir ve konakçıya özgüdür (12). Sağlıklı bireylerin mikrobiyotasında simbiyont ve patobiyont kompozisyonu dengeli 
bir dağllım göstermektedir. Disbiyoz; simbiyont ve patobiyont kompozisyon arasındaki dengenin bozulması ve patojen mikroorganizmaların artış göstermesi olarak tanımlanmaktadır (13). Fenotip, yaş, doğum şekli, fiziksel aktivite yetersizliği, sigara kullanımı, alkol tüketimi ve beslenme alışkanlıkları mikrobiyal kompozisyonu etkileyen en önemli faktörlerdir (14). Bilim dünyası son yıllarda bağırsak mikrobiyotasının sağlık ve hastalıklardaki rolünün açıklığa kavuşturulması yönündeki çalışmalara ağırlık vermektedir. Disbiyoz gelişiminin bağırsak geçirgenliğinde, endotoksemide, enerji üretiminde, adipozitede ve pro-inflamatuar sitokin üretiminde artışa neden olduğu ve böylece temelinde sistemik inflamasyonun yer aldığı KVH, obezite, diyabet, bazı kanser türleri, romatoid artrit, alkole bağlı olmayan karaciğer yağlanması gibi hastalıkların etyopatogenezinde rolü olduğu bildirilmiştir (15).

\section{Beslenmenin Mikrobiyota Üzerine Etkileri}

Beslenme mikrobiyota kompozisyonunu etkileyen en önemli faktörlerden biridir (Şekil 1). Mikrobiyota kompozisyonunun beslenme alışkanlıklarına bağlı olarak değişiklik gösterebileceği ve mikrobioyota kompozisyonundaki değişikliğin besin ögesi biyoyararlılığını etkileyebileceği yapılan araştırmalarla ortaya konmuştur. Bu nedenle bağırsak

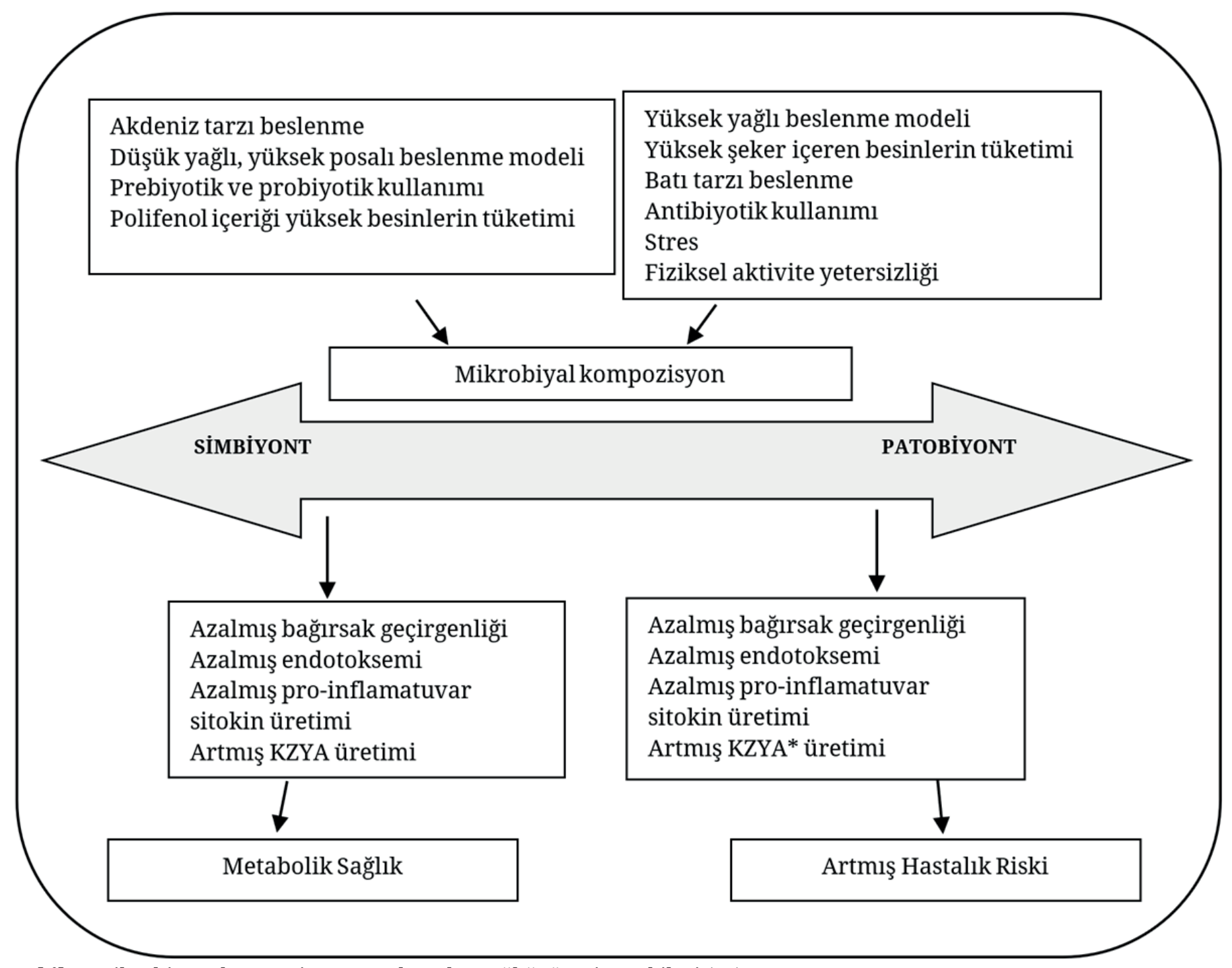

Şekil 1. Mikrobiyota kompozisyonu ve konakçı sağlığı üzerine etkileri (16). 
mikrobiyotası ve beslenme alışkanlıkları arasında çift yönlü ve güçlü bir ilişki vardır $(16,17)$.

\section{Polifenoller ve Mikrobiyota}

Doğal olarak içerdikleri aktif bileşenleri ile sağlıklı beslenmeye katkıda bulunan, iyi hal ve sağlığı geliştirici, hastalık riskini azaltıcı potansiyel etkileri olan besinler fonksiyonel besinler olarak tanımlanmaktadır. Bu besinlerin içeriğinde bulunan besin ögesi olan veya olmayan, tüketildikleri zaman sağlığı olumlu yönde etkileyen bileşenler ise 'biyoaktif besin bileşeni' olarak adlandırılmaktadır (18). Polifenoller çoğunlukla sebze ve meyvelerde bulunan ve yapısında birden fazla fenolik grup bulunduran biyoaktif besin bileşenleridir (19). İçerdikleri fenol halkalarının sayısına ve bu halkaları bağlayan yapısal elementlere göre sinıflandırılabilirler. Polifenollerin çoğunluğu glikozitler, esterler, hidroksil formunda bulunurlar (20). Fenolik bileşiklerin arasındaki yapısal farklılıklar biyoyararlanımlığını etkilemektedir. Emilimleri ve biyoyararlılığı için metabolizmaları, enterositlerde mikrobiyal enzimler yoluyla polimerik, glikosillenmiş veya esterleşmiş yapının hidrolizi ile başlamaktadır (21). Diyetle alınan polifenollerin \%5-10'u ince bağırsaktan dekonjugasyon sonrası doğrudan emilir. İnce bağırsaktan emilen metabolitler enterosit ve hepatositlerde Faz I ve Faz II biyotransformasyonlarına katılarak suda çözünebilen

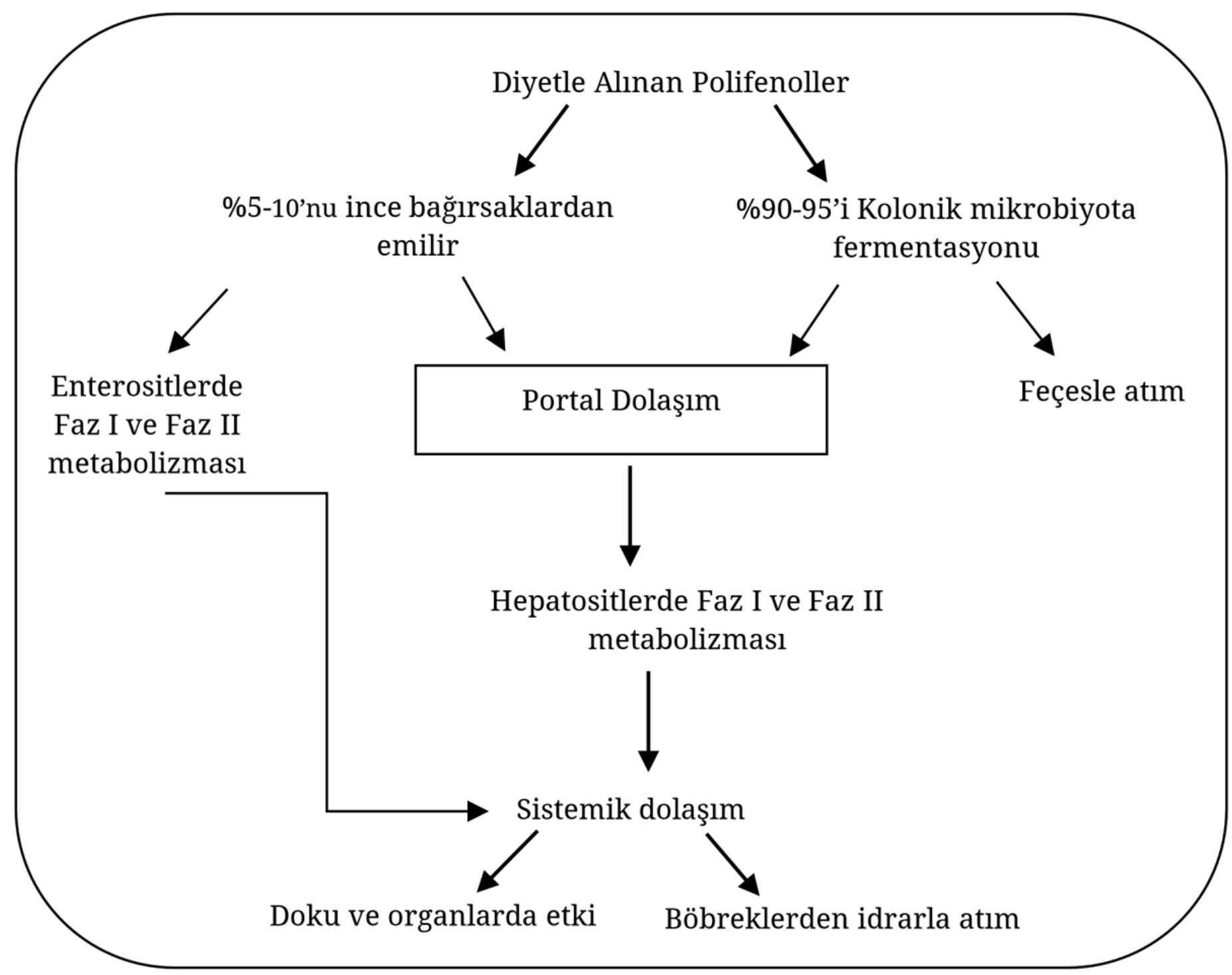

Şekil 2. Polifenol metabolizması (22). 
ve sistemik dolaşıma daha hızlı katılabilen metabolitler oluşur. Emilemeyen polifenoller (\%90-95’i) kolondaki bakteriler tarafından enzimatik değişikliğe uğrar ve fizyolojik önemi olan metabolitler üretilir. Kolonda üretilen bu metabolitler ya emilir ya da feçes veya idrar yoluyla vücuttan atılır (22).

Polifenoller ve mikrobiyota arasında polifenollerin kolonik bakteriler tarafından insan sağlığını olumlu yönde etkileyen metabolitlerine çevrilmesi ve bu metabolitlerin kolonik mikrobiyota üzerine olan etkileri nedeni ile çift yönlü bir ilişki görülmektedir (10). Polifenollerin mikrobiyota kompozisyonu üzerine olan etkileri; i) kolonda yaşayan yararlı bakterilerin üremesini stimüle etmesi, ii) patojen bakterilerin inhibisyonunu sağlaması, iii) enterosit gelişimi üzerine olumlu etkilerinin olması şeklinde siralanabilir $(23,24)$.

\section{Mikrobiyota ve Diyabet}

Sanayileşme, sağlıksız beslenme alışkanlıkları ve sedanter yaşam tarzına bağlı olarak KVH, obezite, tip 2 diyabet ve kanser gibi bulaşıcı olmayan hastalıkların prevalansında artış olduğu vurgulanmaktadır (6). Yaşam tarzı değişikliği ile tip 2 diyabet ve onunla aynı risk faktörlerini taşıyan bulaşıcı olmayan diğer kronik hastalıkların önlenebildiği veya hastalık geliştikten sonra yaşam tarzı değişikliği ile hastalığın yönetimi sağlanarak komplikasyon riskinin azaltılabileceği öngörülmektedir $(25,26)$.

Disbiyoz gelişimine bağlı olarak sindirim sistemindeki fizyolojik değişim, kısa zincirli yağ asitlerinden enerji hasatının artmasına, açlıkla indüklenen adipoz faktörü (Fasting-Induced Adipose Factor [FIAF]) düzeylerindeki ve adenozin monofosfat aktive edici protein kinaz (AMPK) sinyalizasyonundaki azalmaya bağlı olarak artmış lipogeneze, lipopolisakkaritlerin (LPS) immün sistemi aktive etmesine ve proinflamatuar sitokin üretiminin artmasina neden olmaktadır. Böylece disbiyoz obezite, diyabet ve insülin direnci patogenezinde önemli bir rol üstlenmektedir $(27,28)$. İnsan mikrobiyotası üzerinde yapılan araştırmalarda obez ve tip 2 diyabetli bireylerin mikrobiyotasindaki Bacteroides ve Firmicutes oranının ters ilişkili olduğu görülmüştür. Mikrobiyal kompozisyondaki Bacteroides/Firmicutes oranı arasındaki farklılık nedeni ile mi hastalık gelişmektedir yoksa bireysel mikrobiyotanın bu şekilde olması bireyleri hastalığın gelişimine yatkın hale mi getirmektedir sorusuna yanıt verilebilmesi için daha ileri çalışmaların yapılması gerekmektedir (14).

\section{İnflamasyon ve Tip 2 Diyabet}

Gram negatif bakterilerin hücre duvarı bileşenleri olan LPS’lerin düzeylerindeki artış endotoksemi olarak adlandırılır. Bağırsak bariyer bütünlüğündeki bozulma obezite ve tip 2 diyabet gelişimine katkıda bulunan endotokseminin en önemli sebebidir. Bağırsak bariyer bütünlüğü epitelyal hücreler arasındaki sıkı bağlantı proteinleri (claudin, occludin, zonula occludins) tarafından regüle edilmektedir. Bu proteinlerin ekspresyonunda ve konumlanmasındaki bozukluk bağırsak geçirgenliğinin artmasına neden olur. Antibiyotik kullanımı, aşırı yağlı beslenme gibi çevresel faktörlere bağlı olarak sıkı bağlantı proteinlerinde (Zonula occludins-1 [ZO-1], claudin ve occludin) bozulmaların meydana gelmesi, bağırsak bariyer bütünlügünün sağlanmasında rol alan endokannabinoid (eCB) sistemin bozulması, LPS detoksifikasyonundan sorumlu intestinal alkalin fosfataz (IAP) enziminin aktivasyonundaki azalma endotoksemi gelişimine neden olmaktadır. Artmış endotoksemi düşük düzeyde inflamasyona neden olarak tip 2 diyabet ve obezite gelişimine sebep olur. Metabolik endotoksemiye bağlı artış gösteren proinflamatuar sitokin (İnterlökin-1[IL-1], İnterlökin-6 [IL-6], Tümor Nekrozis Faktör-a [TNF-a]) üretimi; insülin sinyalizasyonunun bozulmasina neden olarak insülin direnci ve tip 2 diyabet patagonezinde yer almaktadır (29-31).

\section{Mikrobiyota ve Diyabet}

Yaşamın ilk yıllarındaki yetersiz beslenmenin, yüksek miktarda gluten ve inek sütü içeren beslenme alışkanlıklarının bağırsak mikrobiyota 
kompozisyonunda değişikliğe neden olarak otoimmün hastalıkların gelişimine duyarlılığı artırabileceği ileri sürülmektedir (32,33). Epitelyal hücreler arasına yüksek miktarda gliadin ve $\beta$-kazein geçişi dentritik hücrelerin ortama ve $\alpha$ - pankreatik lenf nodlarına göç etmesine neden olur (34). Dentritik hücrelerin migrasyonuna bağlı olarak $\mathrm{T}$ hücreler aktifleşir ve adacık antikorlarına karşı antikor gelişimine; tip 1 diyabet ve erişkinde latent otoimmun diyabet (Latent Autoimmun Diabetes in Adults [LADA]) gelişimine katkıda bulunur. Disbiyoza bağlı olarak dolaşımdaki miktarı artan LPS'ler, CD14/TLR4 kompleksi ile etkileşime geçerek nükleer faktör kapa $B(N F k B)$ ve aktive edici protein 1 (AP-1) ekspresyonunda artış görülmesine ve IL-6, IL-1, TNF- $\alpha$ ve peroksizom proliferatör-aktive reseptör gamma (PPAR- $\gamma$ ) gibi proinflamatuvar sitokinlerin ve adipojenezden sorumlu genlerin seviyelerinde artış görülmesine sebep olur. Pro-inflamatuar sitokinlerin düzeylerindeki artışa bağlı olarak meydana gelen düşük düzeyde inflamasyon insülin direnci ve tip 2 diyabet gelişimine katkıda bulunan en önemli faktörlerden biridir $(35,36)$.

\section{Mikrobiyata, Kısa Zincirli Yağ Asitleri ve İnsülin Direnci}

Sindirilmeyen karbonhidratlar kolonik mikrobiyota tarafından fermente edilir. Sindirilmeyen karbonhidratların fermantasyonu sonucu kısa zincirli yă̆ asitleri (KZYA) olan bütirat, asetat, propiyonat oluşur. KZYA'ların glukoz ve enerji metabolizması üzerine etkileri vardır. Bütirat bağırsak epitelyum hücreleriiçinenönemlienerjikaynağılmanınyanında intestinal mukozada $G$ protein aracılı reseptörlere (GPR41, GPR43) bağlanarak glukagon benzeri peptid -1(GLP-1) ve peptid YY (PYY) seviyelerinde artışa neden olur. GLP-1 ve PYY seviyelerindeki artış insülin duyarlılığında artışa neden olur. Propiyonat ve asetat karaciğerde lipogenez ve glukoneogenez için substrat olarak kullanılmaktadır. Çalışmalarda, disbiyotik mikrobiyota varlığında insan sağlığını olumlu yönde etkileyen bu fizyolojik etkinin bozulduğu, insülin direnci ve obezite gelişimine katkıda bulunabileceği ileri sürülmektedir (37-39).

\section{Polifenoller, Mikrobiyota ve Diyabet}

Son yıllarda yapılan çalışmalar diyetle alınan polifenollerin $\mathrm{KVH}$, tip 2 diyabet, obezite, artrit, inflamatuvar bağırsak hastalıkları, Alzheimer ve Parkinson gibi birçok kronik hastalığın önlenmesi ve tedavisinde önemli bir yeri olduğunu vurgulamaktadır. Sebze ve meyvelerde yüksek miktarda bulunan polifenoller anti-diyabetik, antiinflamatuvar, anti-fungal, anti-mikrobiyal ve antihipertansif etki göstererek insan sağlığını olumlu yönde etkileme potansiyeline sahiptirler. Polifenoller hem mikrobiyal kompozisyonunu hem de glukoz homeostazını ve insülin duyarlılığını etkileyerek diyabetin önlenmesi veya yönetiminin sağlanmasına katkıda bulunabilirler. Karbonhidratların sindiriminiemilimini, metabolizmasını, glukozun dokular tarafından kullanılmasını ve insülin sinyalizasyonunu etkileyerek anti-diyabetik etki gösterebilirler (Şekil 3) $(40,41)$. Yapılan araştırmalar polifenollerin disbiyozun gelişimine neden olabileceğini ortaya koyarken, tip 2 diyabetli bireylerin mikrobiyotasindaki bacteroidetes/ firmucutes oranının tip 2 diyabetliolmayan bireylerden farklılık gösterdiğini ve bu oranın farklı olmasının da hastalık gelişimine katkıda bulunabilecek bir faktör olduğuna dikkat çekmektedir (42).

\section{SONUÇ VE ÖNERİLER}

Hem mikrobiyota ve polifenoller arasinda hem de diyabet ve mikrobiyota arasında çift yönlü bir ilişki olduğu görülmektedir. Polifenollerin mikrobiyota, glukoz homeostazı, insülin duyarlılığı üzerine olumlu potansiyel etkileri vardır. Polifenol içeriği yüksek olan sebze ve meyveler aynı zamanda posadan zengin, enerji yoğunluğu düşük besinlerdir. Polifenol içeriği yüksek olan besinlerin kan şekeri regülasyonunun ve hedeflenen vücut ağırlığı kaybının sağlanmasında veya hastalıkla ilişkili olabilecek komplikasyonların geciktirilmesinde olumlu etki gösterme potansiyelleri olduğundan bireyselleştirilmiş tıbbi beslenme tedavisinde polifenollere mutlaka yer verilmelidir. 


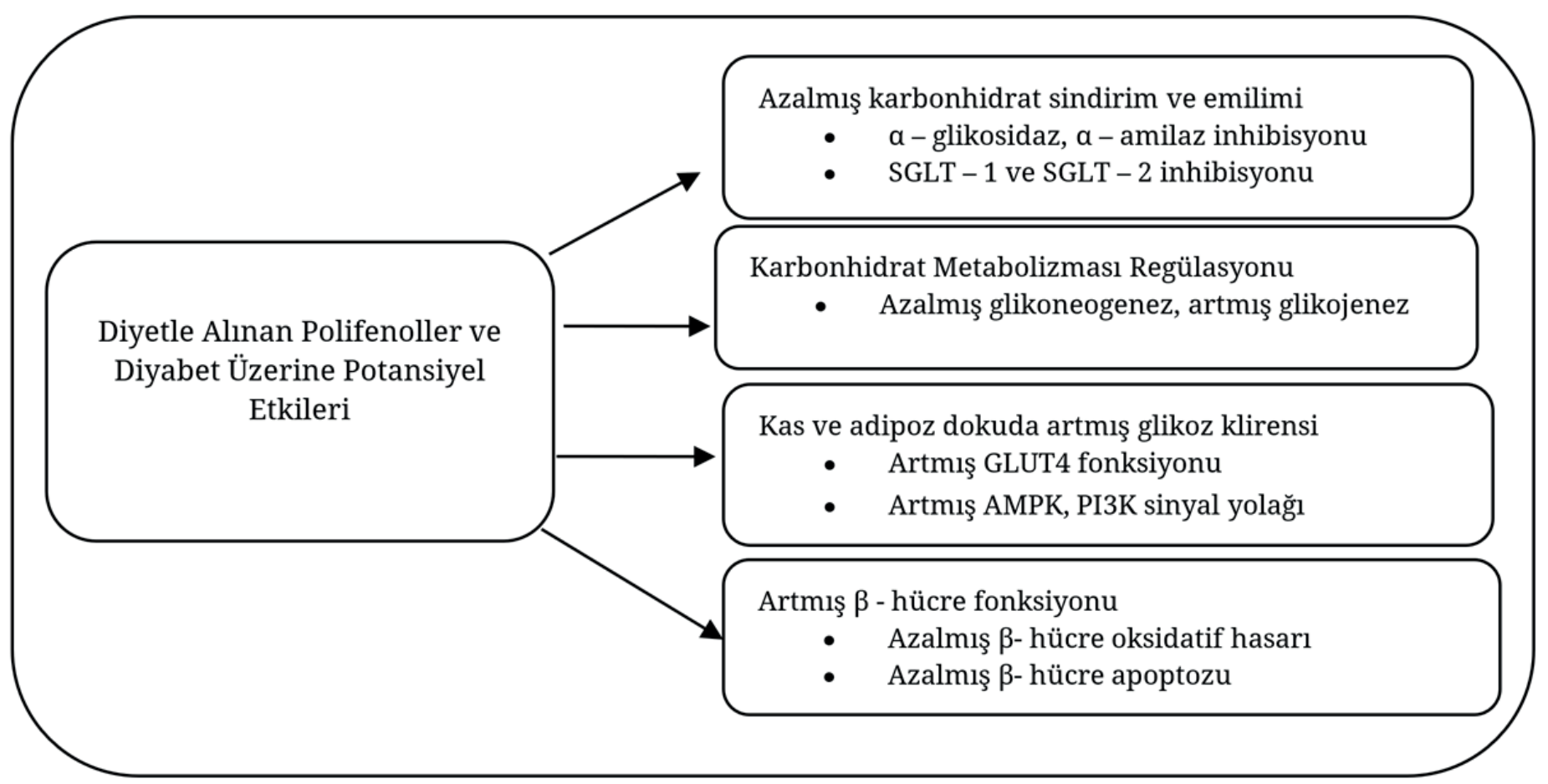

Şekil 3. Polifenollerin diyabet üzerine potansiyel etkileri (41). *SGLT:Sodyum Glukoz transporter, GLUT4:glukoz taşlyıcı 4

Çıkar çatışması - Conflict of interest: Yazarlar çıkar çatışması olmadığını beyan ederler. - The authors declare that they have no conflict of interest.

\section{KAYNAKLAR}

1. Koboziev I, Webb CR, Furr LK, Grisham BM. Role of enteric microbiota in intestinal homeostasis and inflammation. Free Radic Biol Med. 2014; 68: 122-33

2. Tremaroli V, Bäckhed F. Functional interactions between the gut microbiota and host metabolism. Nature. 2012;489:242-9.

3. Cho I, Blaser JM. The Human Microbiome: at the interface of health and disease. Nat Rev Genet. 2012;13(4):260-70.

4. Shortt C, Hasselwander O, Meynier A, Nauta A, Fernandez NE, Putz P, et al. Systematic review of the effects of the intestinal microbiota on selected nutrients and non-nutrients. Eur J Nutr. 2018;57:25-49

5. Danneskiold-Samsøe NB, Dias de Freitas Queiroz Barros $\mathrm{H}$, Santos R, Bicas JL, Cazarin CBB, Madsen L, et al. Interplay between food and gut microbiota in health and disease. Food Res Int. 2019;115:23-31.

6. International Diabetes Federation . IDF Diabetes Atlas, 8th ed., 2017. www.diabetesatlas.org

7. Williamson AD. Prevention of type 2 diabetes: what is the right target population?.Expert Rev Endocrinol Metab. 2018;13(6):295-305.
8. XU X, Wang Z, Zhang X. The human microbiota associated with overall helath. Crit Rev Biotechnol. 2015;35(1):12940 .

9. Maukonen J, Saarela M. Human gut microbiota: does it matter? P Nutr Soc. 2015;74:23-36.

10. Duenas M, Gonzales MI, Cueva C, Giron J, Patan SF, Buelga SC, et al. A Survey of modulation of gut microbiota by dietary polyphenols. BioMed Res Int. 2014;2015:1-15.

11. Eberl G. A new vision of immunity: homeostasis of the superorganism. Nature. 2010;3: 450-60.

12. Lau K, Srivatsav V, Rizwan A, Nashed A, Liu R, Shen R, et al. Bridging the gap between gut microbial dysbiosis and cardiovascular diseases. Nutrients. 2017;9:1-17.

13. Round JL, Mazmanian KS. The gut microbiota shapes intestinal immune responses during health and disease. Nat Rev Immunol.2009;9:313-24.

14. Boulange LC, Neves LA, Chilloux J, Nicholson, Dumans EM. Impact of the gut microbiota on inflammation, obesity and metabolic disease. Genome Med. 2016;8(42):1-12.

15. Nagpal R, Yadav H, Marota F. Gut microbiota: the nextgen frontier in preventive and therapeutic medicine? Front Med. 2014;1(15):1-4.

16. Frint JH, Scott PK, Louis P, Duncan SH. The role of gut microbiota in nutrition and health. Nat. Rev. Gastroenterol. Hepatol 2012; 9:577-89.

17. Parekh PJ, Arusi E, Vinik AI, Johnson DA. The role and influence of gut microbiota in pathogenesis and 
magement of obesity and metabolic syndrome. Front. Endocrinol 2014;5:47

18. Visioli F, , De La Lastra CA, Lacueva CA, Avıram M, Calhau C, Cassano A, et al. Polyphenols and human health: A prospectus. Crit. Rev. Food Sci. Nutr. 2011;51:524-46.

19. Landete JM. Dietary intake of natural antioxidants: Vitamins and polyphenols. Crit. Rev. Food Sci. Nutr. 2013:53(7);706-21.

20. Santangelo C, Zicari A, Mandosi E, Scazzocchio B, Mari E, Morano S, et al. Could gestational diabetes mellitus be managed through dietary bioactive compounds? Current knowlaedge and future perpectives. Br J Nutr 2016;115:1129-44.

21. Bolca S, Wiele VT, Possemiers S. Gut metabotypes govern health effects of dietary polyphenols. Curr Opin Biotechnol. 2013;24:220-

22. Cardona F, Lacueva-Andres C, Tulipani S, Tinahones FJ, Queipo-Ortuno MI. Benefits of polyphenols on gut microbiota and implications in human health. J Nutr Biochem. 2013;24:1415-22.

23. Czaplinska-Kalunza J, Gatarek P, Chartrand MS, Dadar $\mathrm{M}$, Bjorklund $\mathrm{G}$. Is there a relationship between intestinal microbiota, dietary compound and obesity? Trends Food Sci Technol 2017; 70:105-13.

24. Conlon AM, Bird AR. The impact of diet and lifestyle on gut microbiota and human health. Nutrients.2015;7:17-44.

25. Tang WH, Kitai T, Hazen SL. Gut microbiota in cardiovaskuler health and disease. Circ Res. 2017 Mar 31;120(7):1183-1196

26. TC. Sağlık Bakanlığı. Hacettepe Üniversitesi . Türkiye’ye Özgü Beslenme Rehberi, Ankara, T.C. Sağlık Bakanlığı, 2004

27. Tavares da Silvia S, Santos CA, Bressan J. Intestinal microbiota; relevance to obesity and modulation by prebiotics and probiotics. Nutr Hosp. 2013;28(4):103948.

28. Everard A, Cani DP. Diabetes, obesity and gut microbiota. Best Pract Res Clin Gastroenterol 2013;27:73-83.

29. Zhang Y, Zhang H. Microbiota associated with type 2 diabetes and its related complications. Food Sci Hum Well 2013:2;167-72.

30. Ye J. Mechanisms of insulin resistance in obesity. Front. Med. 2013;7(1):14-24.
31. Virtanen SM, Nevalainen J, Kronberg-Kippila C, Ahonen S, Tapanainen $\mathrm{H}$, Uusitalo L, et al. et al. Food consumption and advanced $\beta$ cell autoimmunity in young children with HLA- conferred susceptibility to type 1 diabetes: a nested case-control design. Am J Clin Nut .2012;95:471-78.

32. Hamari S, Kirveskoski T, Glumoff V, Kulmala P, Simell O, Knip M, et al. CD+4 T-cell proliferation responses to wheat polypeptide stimulation in children at different stages of type 1 diabetes autoimmunity. Pediatr. Diabetes 2015;6:177-88.

33. Blandio G, Inturri R, Lazzara F, Di RosA M, Malaguarnera L. Impact of gut microbiota on diabetes mellitus. Diabetes Metab. 2016 Nov;42(5):303-15.

34. Kim K, Gu W, Lee I, Joh E, Kim DH. High fat diet-induced gut microbiota exarcerbates inflammation and obesity in mice via the tlr4 signaling pathway. PLoS One. 2012;7(10):e47713.

35. Dhirman RK (Ed). Gut microbiota, inflammation and hepatic encephalopathy: a puzzle with a solution in sight. J Clin Exp Hepatol 2012;3:207-10.

36. Yadav M, Verma KM, Chauhan NS. A review of metabolic potential of human gut microbiome in human nutrition. Arch Microbiol. 2018 Mar;200(2):203-217

37. Sun Y, Jin C, Zhang X, J W, Le J, Ye J. Restoration of GLP1 secretion by berberine is associated with protection of colon enterocytes from mitochondrial overheating in diet-induced obese mice. Nutr. Diabetes 2018;8(53):1-10.

38. Serra D, Almeida ML, Dinis CPT. Dietary polyphenols: A novel strategy to modulate microbiota gut brain axis. Trends Food Sci Technol 2018;78:224-33.

39. Ganesan K, Xu B. A critical review on polyphenols and health benefits of black soybeans. Nutrients 2017; 9(5):455

40. Laparra JM, Sanz Y. Interactions of gut microbiota with functional food components and nutraceuticals. Pharmacol Res. 2010; 61: 219-225

41. Bahadoran Z, Mirmiran P, Azizi F. Dietary polyphenols as potential nutraceuticals in management of diabetes: a review. J Diabetes Metab Disord 2013;12(43):1-9.

42. Allin HK, Nielsen T, Pedersen O. Mechanisms in Endocrinology: Gut microbiota in patients with type 2 diabetes mellitus. Eur J Endocrinol. 2015;172(4):167-77. 